\title{
Estimating the Sensitivity of Mean Annual Runoff to Climate Change using Selected Hydrological Models
}

\author{
Roger N. Jones, Francis H.S. Chiew, Walter C. Boughton, Lu Zhang
}

\author{
Roger N. Jones \\ CSIRO Atmospheric Research \\ PMB1 Aspendale \\ Victoria 3195 \\ Australia \\ roger.jones@csiro.au (corresponding author) \\ Francis H.S. Chiew \\ Cooperative Research Centre for Catchment Hydrology \\ Department of Civil and Environmental Engineering \\ University of Melbourne \\ Victoria 3010 \\ Australia \\ fchs@civenv.unimelb.edu.au \\ Walter C. Boughton \\ Emeritus Professor \\ Griffith University \\ Queensland 4111 \\ Australia \\ walterboughton@bigpond.com \\ Lu Zhang \\ CSIRO Land and Water \\ GPO Box 1666 \\ Canberra \\ ACT 2601 \\ Australia \\ lu.zhang@csiro.au
}

October 2004 


\section{ABSTRACT}

Hydrological model sensitivity to climate change can be defined as the response of a particular hydrological model to a known quantum of climate change. This paper estimates the hydrological sensitivity, measured as the percentage change in mean annual runoff, of two lumped parameter rainfall-runoff models, SIMHYD and AWBM and an empirical model, Zhang01, to changes in rainfall and potential evaporation. These changes are estimated for 22 Australian catchments covering a range of climates, from cool temperate to tropical and moist to arid. The results show that the models display different sensitivities to both rainfall and potential evaporation changes. The SIMHYD, AWBM and Zhang01models show mean sensitivities of 2.4\%, 2.5\% and 2.1\% change in mean annual flow for every $1 \%$ change in mean annual rainfall, respectively. All rainfall sensitivities have a lower limit of $1.8 \%$ and show upper limits of $4.1 \%$, 3.4\% and 2.5\%, respectively. The results for potential evaporation change are $-0.5 \%,-0.8 \%$ and $-1.0 \%$ for every $1 \%$ increase in mean annual potential evaporation, respectively, with changes rainfall being approximately 3 to 5 times more sensitive than changes in potential evaporation for each $1 \%$ change in climate. Despite these differences, the results show similar correlations for several catchment characteristics. The most significant relationship is between percent change in annual rainfall and potential evaporation to the catchment runoff co-efficient. The sensitivity of both A and B factors decreases with an increasing runoff coefficient, as does the uncertainty in this relationship. The results suggest that a firstorder relationship can be used to give a rough estimate of changes in runoff using estimates of change in rainfall and potential evaporation representing small to modest changes in climate. Further work will develop these methods further, by investigating other regions and changes on the subannual scale.

KEY WORDS: Climate change, rainfall, runoff, sensitivity analysis, Australia, watersheds

\section{INTRODUCTION}

During this century, climate change is expected to have widespread impacts on the terrestrial hydrological cycle, affecting water supply and demand in many parts of the world [1]. One way of assessing the likely impacts of climate change on water resources is to apply climate change scenarios to rainfall-runoff models to estimate runoff and streamflow [e.g. 2]. Further modelling is then undertaken to simulate water storage, quality, allocation and use. 
Most catchment-scale hydrological models have been developed to simulate water resources under current climate. Such models are adapted to simulate altered supply under climate change either by perturbing an historical time series by climate change factors, downscaling data from a global climate model (GCM) using statistical, dynamic or hybrid approaches, or by utilising weather-generated data. It is widely accepted by hydrological modellers assessing climate change that the climate uncertainties feeding into rainfall-runoff models are far larger than the hydrological uncertainties within the models themselves: the greatest uncertainties in the effect of climate on streamflow arise from uncertainties in climate change scenarios, as long as a conceptually sound hydrological model is used [1]. Despite this, if a wide range of potential climate change scenarios are used, differences between models remain, and some will be more correct than others.

In 1999, Hulme and Carter [3] wrote that full and systematic treatment of uncertainties in both climate change scenarios and impact response are required in for use in policy-making. However, limited progress in this area has been made since then. The bottleneck lays not so much in the link between hydrology and water resources, but in the characterisations and application of climate change, requiring the pragmatic application of riskanalytic techniques [4]. This in turn will influence hydrological model development and use.

The decision about the type and number of climate scenarios to apply to a hydrological model typically involves a trade-off between representing a broad range of plausible climate change uncertainties and the realistic representation of climate variability within each scenario. Using a larger number of scenarios requires simpler, less resource-intensive methods, while the application of only one or two scenarios allows the use of more realistic methods of downscaling. Thus, the first alternative allows climate uncertainty to be better explored by sacrificing the accuracy of each result, while the latter path provides a better representation of spatial and temporal variability. The first method lends itself to simpler models, while the second is most appropriate for models that are resource hungry, such as complex physically-based models with large data requirements, those that have highly detailed spatial or physical processes and those that require intensive downscaling of input data. This tension is described as one between physical-based modelling and pragmatism [4]. See Katz [5] for a comprehensive discussion on uncertainty analysis that deals with issues of model complexity. 
Both types of model have a useful but somewhat different role in impact assessment. For example, simple models that explore a wide range of uncertainty can be used to rapidly assess the impacts of very different scenarios and test a range of policy options, while physically-based models can potentially assess the joint impacts of land-use change, climate change and atmospheric $\mathrm{CO}_{2}$ impacts on vegetation. In an ideal world, it would be possible to relate the results from simple with those from complex models through a better understanding of hydrological sensitivity to a range of changes including climate.

Several investigations have explored the sensitivity of simple empirical and water balance models. Wigley and Jones [6] developed sensitivity relationships for changes in rainfall, evaporation and $\mathrm{CO}_{2}$ to estimate changes subject to a catchment's runoff co-efficient. Arnell [7] compared a simple monthly water balance model to four different empirical models under climate change, finding large differences between models. These, and similar methods are now largely considered to be inferior to more detailed hydrological approaches $[8,9]$. This has increased the use of daily models such as conceptual lumped parameter and complex spatially distributed models.

The validation of hydrological models under climate change is also problematic because there are no observed results against which they can be compared [8]. Spatially distributed physically-based models are thought to be superior to empiric and conceptual methods, but still require some form of parameterisation [9]. While it is often stated that more physically realistic hydrologic models should be preferred to conceptual models, this hypothesis has not been rigorously tested.

Most catchment-based studies utilising daily data have applied only a few scenarios to each catchment, limiting the opportunity to understand how that catchment may respond to climate change. Examples where a large number of climate scenarios have been applied to a single catchment include guided sensitivity analyses that apply artificial scenarios to a hydrological model to test its sensitivity to climate over a plausible range of climate change [10,11,12,13], proof of concept examples [3, 14] and several more recent risk assessments of water resources that use a Bayesian approach to explore uncertainty [15, 16, 17, 18, 19]. Amongst large scale studies, Arnell [20] has produced a daily global water balance model with a $0.5^{\circ} \times 0.5^{\circ}$ spatial resolution and run it under a range of emission scenarios run through six GCMs with changes for 2020, 2050 and 2080, which stands as the most comprehensive exploration of different climate scenarios at the global scale to date. 
Few studies have methodically assessed intermodel uncertainty across more than one catchment. Boorman and Sefton [21] applied both artificial and climate change scenarios to two rainfall-runoff models for three catchments in the UK finding that they produced widely varying results. Much of this uncertainty was due to model structure, a similar result to that also found by Panagoulia and Dimou [22] based on assessments of two models in two catchments in Greece. Boorman and Sefton [21] recommended that the most appropriate hydrological models be used (simple models that preserve water balance), along with sensitivity analysis, close examination of parameters, data requirements and model initialisation. These and other studies conclude that runoff changes are amplified in proportional terms when contrasted to changes in rainfall (up to a 4.5 multiplier in percentage terms) and that this amplification increased with aridity [e.g. 10, 11, 21].

One way to explore hydrological model sensitivity to climate change is to apply a large number of scenarios in different models over a variety of catchments. In this case, the emphasis is not on the precision of each single scenario, but is instead on exploring a wide range of climatic and hydrological uncertainty. We use this approach for 22 catchments across Australia, undertaking sensitivity analyses using three hydrological models: two lumped simple conceptual daily rainfall-runoff models SIMHYD [23], AWBM [24, 25] and one simple topdown 2 parameter model Zhang01 [26]. We describe how this information may be used to develop simple rule of thumb models that can be applied to make rapid estimates of potential changes in runoff under climate change. The development of such methods offers the promise of a simple empirical approach based on more complex underpinning science, which can be used to explore uncertainty, provide rapid analysis for testing water management policy and provide provisional estimates for change in catchments lacking more data rich models.

\section{APPROACH}

We define hydrological model sensitivity as the response of a particular hydrological model to a known quantum of climate change. Here we look at the sensitivity of mean annual change expressed in terms of changes to precipitation (P), potential evapotranspiration (Ep) and runoff (Q). Most simplified rainfall-runoff models utilise inputs of P and Ep so can be expressed in those terms. We have found that, for a number of assessments, the change in inputs can be related to the Q using a bilinear relationship. For example, Jones [27] coupled a climate change scenario generator to a catchment-scale hydrological model for the Macquarie River in eastern Australia, 
applying over 50 climate scenarios. For changes to mean annual runoff of $<50 \%$, the results could be expressed as:

$\delta \mathrm{Q}=\mathrm{A} \delta \mathrm{P}+\mathrm{B} \delta \mathrm{Ep}$

where $\delta \mathrm{Q}$ is change in mean annual runoff, $\delta \mathrm{P}$ is change in mean annual precipitation, $\delta \mathrm{Ep}$ is change in mean annual potential evapotranspiration, all measured as percentages, and A and B are constants. This relationship performed well over most of the range in potential change for the assessment years of 2030 and 2070 except for exceptionally large decreases in rainfall where the relationship became non-linear [17]. Percent change to mean annual flow was estimated with a standard error of $\pm 2 \%$ mean annual runoff (i.e. an error of $10 \%$ for an estimated change of 20\%). Sensitivity-based approaches using simple models have also been applied for current climate by Milly and Dunne [20] and climate change by Wigley and Jones [6] and Dooge et al. [21].

This simple relationship is used throughout the study to measure model sensitivity to climate inputs. Factor A is a measure of the sensitivity of the model to $\mathrm{P}$ changes and factor B to Ep changes. The use of potential evaporation rather than temperature is preferred because it is a more direct measure of moisture loss from regions that are water-limited rather than energy limited. Although changes in temperature and Ep are highly correlated in higher latitudes, Walsh et al. [30] show that changes to temperature and Ep are largely independent in Australia, and by inference, across much of the low and mid latitudes. Changes in P and Ep in Australia are also co-dependent, whereas changes between temperature and precipitation are independent [as they are for higher latitudes; see 31]. Because most previous studies investigating hydrological model sensitivity are dominated by northern hemisphere assessments that express their results in terms of temperature change rather than $\delta \mathrm{Ep}$, it is difficult to review their results in a form consistent with Equation 1.

The three models used in the sensitivity analysis have all been used widely in Australia. The sensitivity analysis was carried out for 22 catchments over Australia that produce some of the best model calibration results [NashSutcliffe efficiency; 32] of 331 catchments across Australia [33]. They were selected for an efficiency rating for monthly runoff of greater than 0.8 with the SIMHYD model (with one exception), a calibration against at least 15 years of streamflow data and to provide a good representation of different climates across Australia. Cross 
correlation of parameters have not been addressed, as the emphasis has been to produce the best reproduction of streamflow possible.

The sensitivity analysis involved changes in annual P and Ep in increments of 5\% of up to 15\% applied to inputs of daily data and the results are expressed as change in mean annual runoff. Rainfall increments of $-15 \%,-10 \%$, 0 and $+10 \%$ were used and Ep increments of $0,+5 \%$ and $+10 \%$ for a total of 12 samples for each model run in each catchment. The constant factors, A and B, are determined by method of least squares, by minimising the sum of squares of the difference between $\delta Q$ determined from the AWBM and SIMHYD modelling results and $\delta \mathrm{Q}$ estimated by equation (1). In most cases, the $\mathrm{R}^{2}$ value ranged between $0.97-0.999$ and standard error was $<2 \%$ of mean annual flow.

\section{DATA}

Daily rainfall, mean monthly areal potential evapotranspiration (APET) and monthly streamflow data from 22 catchments across Australia are used for this study (see Table 1 for catchment locations and characteristics). They are part of the data set of 331 unimpaired catchments used in an Australian Land and Water Resources Audit study [see 33]. “Unimpaired” is defined as data from unregulated rivers or where regulation changes the natural monthly streamflow volumes by less than five percent. The determination of whether the streamflow data is unimpaired is based on local knowledge of the respective water agencies and/or whether there is a significant dam upstream of the gauging station. The monthly streamflow time series data, all exceeding 15 years in length, were obtained from state water agencies.

$<<$ Insert Table 1 about here $>>$

Continuous daily rainfall and APET data are required as inputs into daily rainfall-runoff models. The source of the daily rainfall data is the Queensland Department of Natural Resources, Mines and Energy $0.05^{\circ} \mathrm{x} 0.05^{\circ}$ (about $5 \mathrm{~km}$ x $5 \mathrm{~km}$ ) interpolated gridded rainfall data based on over 6,000 rainfall stations in Australia (see www.nrme.qld.gov.au/silo). The interpolation uses Ordinary Krigging of monthly rainfall data, and a variogram with zero nugget and a variable range. The monthly rainfall for each $5 \mathrm{~km}$ x $5 \mathrm{~km}$ point is then disaggregated to 
daily rainfall using the daily rainfall distribution from the station closest to the point. The lumped catchmentaveraged daily rainfall used here is estimated from the daily rainfall in $5 \mathrm{~km}$ x $5 \mathrm{~km}$ points within the catchment.

Compared to rainfall, evapotranspiration has little influence on the water balance at a daily time scale. The interannual variability of APET is also relatively small (typically less than 0.05 ). For these reasons, the use of mean monthly APET is sufficient for most rainfall-runoff modelling applications. The 12 mean monthly APET values used here are obtained from the evapotranspiration maps in the Climatic Atlas of Australia [34]. The APET for the maps are derived using Morton’s [35] wet environment evapotranspiration algorithms.

\section{HYDROLOGICAL MODELS}

\section{SIMHYD}

The structure of the simple lumped conceptual daily rainfall-runoff model, SIMHYD, is shown in Figure 1, with its seven parameters highlighted in bold italics.

In SIMHYD, daily rainfall first fills the interception store, which is emptied each day by evaporation. The excess rainfall is then subjected to an infiltration function that determines the infiltration capacity. The excess rainfall that exceeds the infiltration capacity becomes infiltration excess runoff. Moisture that infiltrates is subjected to a soil moisture function that diverts the water to the stream (interflow), groundwater store (recharge) and soil moisture store. Interflow is first estimated as a linear function of the soil wetness (soil moisture level divided by soil moisture capacity). The equation used to simulate interflow therefore attempts to mimic both the interflow and saturation excess processes (with the soil wetness used to reflect parts of the catchment that are saturated from which saturation excess runoff can occur). Groundwater recharge is then estimated, also as a linear function of the soil wetness. The remaining moisture flows into the soil moisture store.

Evapotranspiration from the soil moisture store is estimated as a linear function of the soil wetness, but cannot exceed the atmospherically controlled rate of areal potential evapotranspiration. The soil moisture store has a finite capacity and overflows into the groundwater store. Baseflow from the groundwater store is simulated as a linear recession from the store. 
The successful calibration (and verification) of SIMHYD on these 22 and many other Australian catchments are described in [23] and [33]. These 22 catchments produce Coefficient of Efficiency measurements of between 0.75 and 0.97 , averaging 0.91

$<<$ Insert Figure 1 about here $>>$

\section{AWBM}

The structure of AWBM is shown in Figure 2. AWBM considers the catchment as having three partial areas (A1, A2, A3), each with its own storage capacities (C1, C2, C3). Each partial area is treated separately. The number of partial areas chosen is a pragmatic choice to reflect sufficient skill to simulate runoff without adding too may parameters and facing the risk of over-optimisation [25]. Daily rainfall fills the stores, with the spills becoming rainfall excess. A portion of the rainfall excess (baseflow index times rainfall excess) flows to the groundwater store, and the remainder becomes surface runoff. Baseflow from the groundwater store is simulated as a linear recession from the store. Evapotranspiration from all three stores occurs as a linear recession limited by the difference between field capacity and zero storage as a proportion of the potential rate. The total runoff is the sum of surface runoff and baseflow.

A simplified and robust version of AWBM [UGAWBM3 - see 25) is used here. It has three parameters: average surface store capacity $\left(\mathrm{C}_{\text {ave }}\right)$; baseflow index $(\mathrm{BFI})$ and baseflow recession constant $\left(\mathrm{K}_{\mathrm{b}}\right)$. The three partial areas are set to default values and the storage capacities are determined from the average surface store capacity (see Figure 2).

In UGAWBM3, the parameter $\mathrm{C}_{\text {ave }}$ is determined from a set of daily rainfall and runoff data, such that the total modelled runoff is the same as the total recorded runoff. The remaining two parameters, BFI and $\mathrm{K}_{\mathrm{b}}$, are then optimised to provide the best match between the modelled and recorded daily runoffs. The 22 catchments produce Coefficient of Efficiency measurements of between 0.65 and 0.95, averaging 0.86.

$<<$ Insert Figure 1 about here $>>$ 


\section{Zhang01}

The Zhang01 water balance model was devised to assess the response of catchments to vegetation change [26]. It is an equilibrium response model consistent with earlier equilibrium models such as Budyko[36] which assumes that groundwater recharge and discharge processes are negligible such that:

$\mathrm{Et} / \mathrm{P}=\mathrm{f}(\mathrm{Ep} / \mathrm{P})$ 1

where Et is evapotranspiration and the ratio of $\mathrm{Et} / \mathrm{P}$ is a function of vegetation acting on net radiation through surface albedo. However, the size of Et/P is also a function of the access of vegetation to soil moisture, where in most cases it is more a function of rooting depth, rather than the size of the soil moisture itself. Zhang et al. [26] proposed the following rational function:

$$
\frac{E t}{P}=\frac{1+w \frac{E p}{P}}{1+w \frac{E p}{P}+\left(\frac{E p}{P}\right)^{-1}}
$$

Where $\mathrm{w}$ is the plant-available water coefficient which ranges between 0.5 and 2.0 for grassland and forest respectively. This function is most reliable where $\mathrm{Ep} / \mathrm{P} \approx 1$ (ranging from about 0.5 to 2 ; i.e. in most catchments where water harvesting is carried out). This model was tested on 250 catchments worldwide where slopes were gentle, rainfall was the dominant form of precipitation and soil thickness was above $2 \mathrm{~m}$ [26]. The root mean square error between observations of Et/P for these catchments and the model was $6 \%$.

Estimates of Ep used in Ep/P were calculated by Morton’s [35] wet environment evapotranspiration algorithms as previously described. These estimates are slightly different to those calculated using the Priestly-Taylor method [37] used by Zhang et al. [26] but will produce similar results. Accordingly, the model was tested for each of the 22 catchments in Table 1. For each of the catchments, w was adjusted so that simulated runoff equalled observed runoff. This maintained w in the range of 0.5 to 2.0 for 14 of the 22 catchments, 3 were $<0.5$ and 5 were $>2.0$. Although a $\mathrm{w}>2$ is not physically realistic, there are perhaps other reasons for these 
relationships. For example, much of the Mt Emu Creek catchment is not linked to the stream network $(\mathrm{w}=5)$ and much of the Todd River catchment is bare soil $(\mathrm{w}=0.15)$. By manipulating $\mathrm{w}$ to reproduce current streamflow, we are assuming that the sensitivity under climate change is not unduly altered from what it otherwise would be.

\section{RESULTS}

\section{Sensitivity analyses}

Table 2 lists the A and B factors for each of the models over the 22 catchments, while Figure 3 shows them in graphical form.

All three models show that runoff is more sensitive to changes in rainfall (Average A factor of 2.1 to 2.5) than to changes in APET (Average B factor of -0.5 to -1.0). Sensitivity is measured as percent change in mean annual runoff for a $1 \%$ change in mean annual $\mathrm{P}$ or Ep. The sensitivity of runoff to rainfall is similar in the SIMHYD and AWBM models (Average A factor of 2.5 and 2.4 respectively) and smaller in the Zhang01 model (Average A factor of 2.1).

The models show less agreement in runoff sensitivity to changes in APET. The runoff sensitivity to APET is greatest in the Zhang01 model (Average B factor of -1.0), followed by AWBM (Average B = -0.8) and SIMHYD (Average B = -0.5).

The variability in the A and B factors across catchments (measured as the standard deviation of values for the 22 catchments) for the SIMHYD and AWBM models are similar, and more variable that the Zhang01 model. This result is expected because Zhang01 produces results based on global average response, whilst SIMHYD and AWBM are calibrated to individual catchments and model runoff on a daily time step

$<<$ Insert Table 2 about here $>>$

$<<$ Insert Table 3 about here $>>$ 
The results in Table 2 are highly correlated, showing the hydrological models largely agree on which catchments are more sensitive to change and those that are less sensitive (Table 3). The correlations between the A factors are 0.82 and 0.83 for the three models. For the B factors, the correlation between SIMHYD and AWBM is 0.66 and both SIMHYD and AWBM have a 0.46 correlation with the Zhang01 model.

The A and B factors also correlate with a wide range of both hydroclimatic and physical catchment characteristics. Correlations between A factor and rainfall are negative (-0.42 to -0.53$)$, increasingly negative for runoff $(-0.72$ to -0.78$)$ and highest for runoff as a percentage of rainfall $(-0.83$ to -0.92$)$. Correlations are also negative for leaf area index, proportion of woody vegetation and plant water-holding capacity (not shown). These negative correlations imply that hydrological sensitivity decreases with higher amounts of land cover and soil moisture. Further tests described in the next section suggest that this outcome is dominated by the increasing coefficient of runoff occurring under wetter conditions, and is not due to vegetation and soil-water relationships.

The B factor is less sensitive to catchment characteristics, and is most highly correlated with annual mean rainfall, percent runoff and vegetation characteristics. $\delta$ Ep sensitivity is also model dependent, being least sensitive to SIMHYD, AWBM and Zhang01 in that order, due to the way that the models utilise Ep. SIMHYD evaporates at a reduced level at low soil moisture, AWBM evaporates at the areal potential rate between field capacity and wilting point and Zhang01 is tuned to the Ep/P ratio, so is the most sensitive to change. Sensitivities for both A and B factors as a function of percentage runoff are shown in Figure 4. The negative correlations between the A value and runoff and the positive correlations between the B value show that as rainfall, runoff and the percentage of runoff increases, the relative sensitivity of the model to proportional change reduces.

$<<$ Insert Table 4 about here $>>$

\section{Further tests}

Two further sensitivity tests were run with the A and B sensitivity factors for each of the 22 catchments for each of the three hydrological models. The first was a drier scenario exploring a decrease in $\mathrm{P}$ of $-15 \%$ and increase in Ep of $+15 \%$. The second test increased both P and Ep by 10\%. These tests allow further comparison of the 
sensitivity of each model (Table 5). The factors contributing to those relative sensitivities are also briefly explored.

Table 5 shows how the models perform for both the drier and wetter scenarios. Under strong drying, SIMHYD is the least sensitive model and AWBM is the most sensitive. SIMHYD is the most sensitive model to the wetter scenario and the Zhang01 model is the least sensitive. SIMHYD shows the most sensitivity to $\delta \mathrm{P}$, although AWBM is close and Zhang01 is the least sensitive. The Zhang01 is the most sensitive to $\delta$ Ep, while AWBM is next and SIMHYD is the least sensitive.

$<<$ Insert Table 5 about here $>>$

The standard deviation of the results for each catchment is related to the sensitivity of the catchment to change, where catchments with larger A and B factors produce larger differences between hydrological models. Although the results for an individual catchment sometimes have high standard deviations, they are highly correlated between catchments (0.76 to 0.78). The average difference between the drier and wetter scenarios for all 22 catchments shows the relative sensitivity of each model to change: 56\% for Zhang01, 63\% for SIMHYD and 66\% for AWBM. The sensitivity for both the AWBM and SIMHYD models are similar over the 22 catchments, while the Zhang01 model, which only two parameters, is the least responsive to different catchment characteristics, mostly due to a reduced sensitivity to $\delta \mathrm{P}$.

The sensitivity of the Zhang01 model is linked to the Ep/P ratio. When Ep/P remains constant (e.g with a 10\% increase in both $\mathrm{P}$ and $\mathrm{Ep}$ ), then A and B will equal 2 and -1 respectively in all cases (i.e. $\delta \mathrm{Q}$ increases by $10 \%$ ). This will constrain the model to a lower range of response for different catchments than the other two models, an expected result with a 2 parameter model.

Figure 5 shows the relationship between A and B factors for this model plotted against Ep/P. It shows that for a given Ep/P ratio, forested catchments are more sensitive to climate change than grassland catchments, in addition to sensitivity increasing with $\mathrm{Ep} / \mathrm{P}$. This is in contrast to the negative/positive correlations for the $\mathrm{A} / \mathrm{B}$ factors (denoting decreasing sensitivity) obtained from the 22 catchments. This difference is due to the autocorrelation between increasing rainfall with LAI and woodiness. In two catchments with the same Ep/P, the more heavily 
vegetated catchment shows greater sensitivity to climate change (in terms of changes to proportion rather than changes in volume). Therefore, runoff from forested catchments is more sensitive to climate change than from grassland catchments, all other things being equal. This also applies for catchments with large soil moisture stores, compared to those with small soil moisture storage.

$<<$ Insert Figure 5 about here $>>$

\section{DISCUSSION}

A better knowledge of hydrological model sensitivity to climate change, undertaken through structured uncertainty analysis, will allow better linkage between simple and complex models. Thus, results from simple and easy to run models, such as lumped parameter and empirical models, can be compared with those from more physically realistic but complex spatially distributed models. This, in turn, may permit the capacity to rapidly estimate changes in some important hydrological variables, such as mean annual runoff, using simple climate change factors such as percentage change in mean annual rainfall and potential evaporation. Although such estimates have low precision with regard to the input scenario, any estimates with a known level of accuracy (e.g. $\pm 10 \%, \pm 20 \%)$ would serve as valuable information when scoping water resource impacts prior to, or in the absence of, a more detailed modelling study. We note that many decisions affecting water resources over the long term are currently being made in regions where detailed assessments have yet to be made. The coverage of complex spatially distributed models is also limited, mainly to developed countries and, in many areas, current water resources remain poorly known [38].

In this initial assessment of hydrological model sensitivity to climate, we have shown that the three models investigated by climate sensitivity analysis all have different hydrological sensitivity. In terms of a broad pattern of results, the SIMHYD model produces a slightly wetter range of outcomes than does AWBM although the range of results is similar. The Zhang01 model produces a reduced range of results due to its only having two parameters. It behaves similarly to AWBM and SIMHYD under conditions of lower P and increased Ep, but produces the driest outcomes under conditions of increasing $\mathrm{P}$ and Ep. This is because the sensitivity is constrained to $\mathrm{A}=2$ and $\mathrm{B}=1$ where the ratio $\mathrm{Ep} / \mathrm{P}$ remains constant. The differences between these models are smaller than those produced by Boorman and Sefton [21]. 
All of the models used in this study are currently being used to carry out hydrological assessments in Australia as are several other types of hydrological model. Results from SIMHYD and AWBM are being used as input into resource allocation models, while the Zhang01 model is being used to look at joint changes in land cover change and climate change. Results from these studies are being used by catchment management bodies, state agencies and water supply corporations to plan and allocate water supply. Knowledge of the relative sensitivities of these models will allow some intercomparisons to be made between the different catchments, and also to infer changes for catchments where assessments have not been undertaken.

The Zhang01 water balance model is part of the Biophysical Capacity to Change (BC2C) model being used to estimate the joint impacts of climate change, reforestation and salinity in the Murray-Darling Basin of eastern Australia. One aim is to link the hydrological impacts of vegetation change with climate change across models with different levels of complexity so that physically explicit methods can be linked to a capacity to carry out rapid analysis with a range of different scenarios, including those testing policy options. The estimation of the joint impact of climate change and land-use change on hydrology and salinity is necessary for estimating changes in stream water quality and rates of land salinisation in much of inland Australia, as is the exploration of policy options to manage risks associated with these changes.

Although integrated models of the land, atmosphere and hydrological processes could be expected to do this, they are process intensive, data hungry and can usually only be run for a limited number of scenarios. Furthermore, Australia currently lacks this modelling capacity, as do many other regions. In developing such models, it would be valuable to link these to much simpler models to maximise the different strengths of separate modelling approaches. Complex physically-based models can estimate the impacts of spatially explicit climate and land-use scenarios but are constrained in the number of simulations that can be run, and in the exploration of uncertainty and different policy options. Simple relationships can be used to explore uncertainty and different policy options with lower precision but greater flexibility. If empirical relationships can be established between simple and more complex models, this will allow the simpler models to be run for a large number of scenarios, exploring a larger range of uncertainty and a broader range of policy options, where the physical response is tuned to that derived from more realistic relationships and models. This is analogous to the 
relationship between complex GCMs and simple climate models as applied by the Intergovernmental Panel on Climate Change.

If we could better understand hydrological sensitivity to climate change and joint climate - land-use change sensitivities, then it would be possible to build simple relationships between input climate parameters and hydrological change that are robust and accurate, if imprecise. This would serve three purposes:

1. To better understand the relationship between hydrological responses that are model specific and those that have a physical basis. Milly and Dunne [28] suggest that A and B factors will have an analytic solution for any catchment, a hypothesis that we are keen to explore.

2. To scope possible hydrological change in the absence of more detailed assessments, and

3. To provide simple but robust relationships for integrated assessment models linking policy responses with ongoing land-use and climate change.

\section{CONCLUSIONS}

Comparisons of the sensitivity of three hydrological models across a range of Australian catchments to changing climate inputs have shown that sensitivity is influenced by model structure, potential errors in climate inputs and/or parameterisation and physical properties, such as vegetation cover, soil moisture storage and runoff as a proportion of total rainfall.

The SIMHYD, AWBM and Zhang01models show mean sensitivities of 2.4\%, 2.5\% and 2.1\% change in mean annual flow for every $1 \%$ change in mean annual rainfall, respectively. All rainfall sensitivities have a lower limit of $1.8 \%$ and show upper limits of $4.1 \%$, 3.4\% and $2.5 \%$, respectively. The results for potential evaporation change are $-0.5 \%,-0.8 \%$ and $-1.0 \%$ for every $1 \%$ increase in mean annual potential evaporation, respectively, with rainfall being approximately 3 to 5 times more sensitive than potential evaporation for each $1 \%$ change in climate.

Hydrological sensitivity has shown to have the following relationships:

- $\quad$ Sensitivity decreases with increasing runoff coefficient, runoff and rainfall. 
- $\quad$ Sensitivity decreases with a higher proportion of woody cover (influencing root depth) and Leaf Area Index.

- $\quad$ Sensitivity increases with increasing Ep/P ratio (catchment dryness)

- $\quad$ Sensitivity increases with soil moisture storage available for evapotranspiration

Further work will be undertaken to explore some of the relationships illustrated in this paper to try and distinguish model-based from physically derived hydrological sensitivity. A further aim is to develop a simple model for estimating mean change in runoff from simple climate parameters to be used in scoping potential hydrological change in the pre-modelling stage of an assessment, in catchments where streamflow data is unavailable or where more physically realistic models have not been constructed. On the basis of this study, the minimum data for such a model would appear to be mean rainfall, mean potential evaporation (areal potential, Priestly-Taylor, Penman-Monteith or similar) and mean runoff.

\section{ACKNOWLEDGEMENTS}

The authors would like to acknowledge Lionel Siriwardena for carrying out the SIMHYD modelling, and several anonymous reviewers for their comments and feedback. This work contributes to the Victorian Government Impacts and Adaptation Program, CSIRO Water for Healthy Country Flagship Program and the National Climate Change Adaptation Program.

\section{REFERENCES}

[1] Arnell NW, Liu C, Compagnucci R, da Cunha L, Hanaki K, Howe C, Mailu G, Shiklomanov I, Stakhiv E. Hydrology and Water Resources, in McCarthy JJ, Canziani O, Leary NA, Dokken DJ, White, KS (eds) Climate Change 2001: Impacts, Adaptation, and Vulnerability. Contribution of Working Group II to the Third Assessment Report of the Intergovernmental Panel on Climate Change, Cambridge University Press, Cambridge: 191-233, 2001

[2] Xu CY. Climate change and hydrologic models: A review of existing gaps and recent research Developments, Water Resour Man 1999;13:369-382. 
[3] Hulme M, Carter TR. Representing uncertainty in climate change scenarios and impact studies. In: Carter TR, Hulme M, Viner D (eds), Representing Uncertainty in Climate Change Scenarios and Impact Studies, Proceedings of the ECLAT-2 Helsinki Workshop, 14-16 April, 1999, Climatic Research Unit, Norwich, UK, 11-37, 1999.

[4] Varis, O, Kajander T, Lemmelä R. Climate and water: from climate models to water resources management and vice versa, Clim Change 2004;66:321-344.

[5] Katz R. Techniques for estimating uncertainty in climate change scenarios and impact studies, Clim Res 2002;20:167-185

[6] Wigley TML, Jones PD. Influences of precipitation changes and direct $\mathrm{CO}_{2}$ effects on streamflow, Nature $1985 ; 314: 149-152$.

[7] Arnell NW. Factors controlling the effects of climate change on river flow regimes in a humid temperate environment, J Hydrol 1992;132:321-342

[8] Leavesly GH. Modeling the effects of climate change on water resources - a review, Clim Change 1994; 28:159-177

[9] Xu XY, Singh VP. Review on regional water resources assessment models under stationary and changing climate, Wat Resour Man 2004;18: 591-612

[10] Karl TR, Riebsame WR. The impact of decadal mean fluctuations in mean precipitation and temperature on runoff: a sensitivity study over the United States, Clim Change 1989;15:423.

[11] Chiew FHS, Whetton PH, McMahon TA, Pittock AB. Simulation of the impacts of climate change on runoff and soil moisture in Australian catchments. J Hydrol 1995;167:121-147. 
[12] Nash LL, Gleick PH. Sensitivity of streamflow in the Colorado Basin to climatic changes, J Hydrol $1995 ; 125: 221$

[13] New M. Climate change and water resources in the southwestern Cape, South Africa, S Af J Sci 2002;98:369-376.

[14] Jones RN Analysing the risk of climate change using an irrigation demand model, Clim Res 2000;14:89_ 100

[15] Fowler A. Potential climate change impacts on water resources in the Auckland Region (New Zealand), Clim Res 1999;11:221-245.

[16] New M, Hulme M. Representing uncertainty in climate change scenarios: a Monte-Carlo approach. Integr. Assess 2000;1:203-213.

[17] Jones RN, Page CM. Assessing the risk of climate change on the water resources of the Macquarie River Catchment, in Ghassemi F, Whetton P, Little R, Littleboy M. (eds), Integrating Models for Natural Resources Management across Disciplines, issues and scales (Part 2), Modsim 2001 International Congress on Modelling and Simulation, Modelling and Simulation Society of Australia and New Zealand, Canberra, 673-678, 2001

[18] Maheepala S, Perera S, Jones RN, Mitchell VG, Wisener T. Assessing the impact of climate change on water supply systems, Australian Water Association Victorian Branch Annual Conference, Albury, October 1820 2001, Australian Water Association Victorian Branch, Caulfield North, Victoria, 8 pp, 2001

[19] Prudhomme C, Jakoba D, Svenssona C. Uncertainty and climate change impact on the flood regime of small UK catchments, J Hydrol 2003;277:1-23

[20] Arnell NW. Effects of IPCC SRES emissions scenarios on river runoff: a global perspective, Hydrol Earth Sys Sci 2003;7:619-641 
[21] Boorman DB, Sefton CEM. Recognising the uncertainty in the quantification of the effects of climate change on hydrological response, Clim Change 1997;35:415 - 434.

[22] Panagoulia D, Dimou G. Sensitivity of flood events to global climate change, J Hydrol 1997;191:208-222.

[23] Chiew FHS, Peel MC, Western AW. Application and testing of the simple rainfall-runoff model SIMHYD. In Singh VP, Frevert DK (eds) Mathematical Models of Small Watershed Hydrology and Applications, Water Resources Publication, Littleton, Colorado, 335-367, 2002

[24] Boughton WC, Chiew FHS. Calibrations of the AWBM for use on Ungauged Catchments. Cooperative Research Centre for Catchment Hydrology, Technical Report 03/15, 2003

[25] Boughton WC. The Australian Water Balance Model, Env Model Software 2004;19: 943-956

[26] Zhang L, Dawes WR, Walker GR. Response of mean annual evapotranspiration to vegetation changes at catchment scale, Wat Resour Res 2001;37:701-708.

[27] Jones RN, Applying a climate scenario generator to water resource policy issues, CSIRO Atmospheric Research Technical Paper No 74, CSIRO Atmospheric Research, Melbourne, 42 pp, 2005.

[28] Milly PCD, Dunne KA. Macroscale water fluxes, 2. Water and energy supply control of their interannual variability, Wat Resour Res 2002;38:10, 1206, doi:10.1029/2001 WR000760.

[29] Dooge ICI, Bruen M, Parmentier, B. A simple model for estimating the sensitivity of runoff to long-term changes in precipitation without a change in vegetation, Adv Wat Resour 1999;23:153-163.

[30] Walsh KJE, Hennessy KJ, Jones RN, McInnes KL, Page CM, Pittock AB, Suppiah R, Whetton PH. Climate change in Queensland under enhanced greenhouse conditions: third annual report, 1999-2000, CSIRO Atmospheric Research, Melbourne, 118 pp, 2001 
[31] Hulme M, Brown O. Portraying climate scenario uncertainties in relation to tolerable regional climate change. Clim Res 1998;10:1-14

[32] Nash JE, Sutcliffe JV. River flow forecasting through conceptual models, Part A: discussion of principles. J Hydrol 1970;10:282-290

[33] Peel MC, Chiew FHS, Western AW, McMahon TA. Extension of Unimpaired Monthly Streamflow Data and Regionalisation of Parameter Values to Estimate Streamflow in Ungauged Catchments. Report prepared for the National Land and Water Resources Audit, 2000. http://audit.ea.gov.au/anra/water/docs/national/streamflow/streamflow.pdf.

[34] Australian Bureau of Meteorology Climatic Atlas of Australia - Evapotranspiration. Australian Government Publishing Service, Canberra, 2001

[35] Morton FI. Operational estimates of areal evapotranspiration and their significance to the science and practice of hydrology, J Hydrol 1983;66:1-76.

[36] Budyko MI, On the determination of evaporation from the land surface, Meterol Gdrol 1955;1:52-58 (in Russian).

[37] Priestly CHB, Taylor RJ. On the assessment of the surface heat flux and evaporation using large-scale parameters, Mon Wea Rev 1972;100:81-92

[38] Hultcrantz K. (Ed.) Comprehensive assessment of freshwater resources of the world: the final report, World Meteorological Organisation and the Stockholm Environment Institute, Stockholm: 1997 
Table 1. Locations and characteristics of the twenty-two catchments used in the study.

\begin{tabular}{|c|c|c|c|c|c|c|c|c|c|}
\hline STATE & Station Name & Latitude & Longitude & $\begin{array}{l}\text { Area } \\
\left(\mathrm{km}^{2}\right)\end{array}$ & $\begin{array}{c}\text { Annual } \\
\text { rainfall } \\
(\mathrm{mm})\end{array}$ & $\begin{array}{c}\text { Annual } \\
\text { runoff } \\
(\mathrm{mm})\end{array}$ & $\begin{array}{c}\text { Annual } \\
\text { runoff } \\
(\%)\end{array}$ & $\begin{array}{l}\text { Annual } \\
\text { APET } \\
(\mathrm{mm})\end{array}$ & $\begin{array}{c}\text { Annual } \\
\text { APET/P } \\
\text { (ratio) }\end{array}$ \\
\hline QLD & Broken R at Old Racecourse & 21.20 & 148.45 & 78 & 1729 & 605 & 35 & 1713 & 1.0 \\
\hline QLD & Kolan R at Springfield & 24.75 & 151.58 & 545 & 946 & 126 & 13 & 1575 & 1.7 \\
\hline QLD & Caboolture R at Upper Caboolture & 27.10 & 152.88 & 98 & 1483 & 418 & 28 & 1563 & 1.1 \\
\hline NSW & Gordon Brook at Fine Flower & 29.41 & 152.65 & 315 & 1154 & 267 & 23 & 1381 & 1.2 \\
\hline NSW & Dingo Creek at Munyaree Flat & 31.84 & 152.29 & 492 & 1408 & 541 & 38 & 1319 & 0.9 \\
\hline NSW & Shoalhaven River at Kadoona & 35.79 & 149.64 & 280 & 965 & 337 & 35 & 1086 & 1.1 \\
\hline NSW & Genoa River at Bondi & 37.17 & 149.32 & 235 & 958 & 219 & 23 & 1059 & 1.1 \\
\hline VIC & Narracan $\mathrm{Ck}$ at Thorpdale & 38.28 & 146.18 & 66 & 1042 & 356 & 34 & 1027 & 1.0 \\
\hline VIC & Bass $\mathrm{R}$ at Loch & 38.38 & 145.56 & 52 & 1140 & 347 & 30 & 1067 & 0.9 \\
\hline VIC & Mount Emu Ck at Skipton & 37.69 & 143.36 & 1251 & 693 & 47 & 7 & 1050 & 1.5 \\
\hline TAS & Swan $\mathrm{R}$ at The Grange & 42.05 & 148.07 & 448 & 763 & 281 & 37 & 910 & 1.2 \\
\hline TAS & Pipers R D/S Yarrow Ck. & 41.07 & 147.11 & 298 & 956 & 317 & 33 & 923 & 1.0 \\
\hline VIC & Yackandandah Ck at Osborne's Flat & 36.31 & 146.90 & 255 & 1066 & 237 & 22 & 1126 & 1.1 \\
\hline VIC & Jim Crow Ck at Yandoit & 37.21 & 144.10 & 166 & 854 & 169 & 20 & 1009 & 1.2 \\
\hline NSW & Adelong Creek at Batlow Road & 35.33 & 148.07 & 155 & 1138 & 256 & 22 & 1138 & 1.0 \\
\hline NSW & Horton River at Horton Dam Site & 30.21 & 150.43 & 220 & 946 & 199 & 21 & 1344 & 1.4 \\
\hline NSW & Bell River at Molong & 33.02 & 148.95 & 365 & 826 & 94 & 11 & 1160 & 1.4 \\
\hline SA & Myponga River at U/S Road Bridge & 35.38 & 138.48 & 76.5 & 820 & 115 & 14 & 1095 & 1.3 \\
\hline NT & Todd R at Wigley Gorge & 23.63 & 133.88 & 360 & 297 & 32 & 11 & 1392 & 4.7 \\
\hline WA & Margaret R at Willmot's Farm & 33.94 & 115.05 & 442 & 1000 & 216 & 22 & 1175 & 1.2 \\
\hline WA & Harvey R at Dingo Rd & 33.09 & 116.04 & 148 & 1052 & 240 & 23 & 1234 & 1.2 \\
\hline NT & South Alligator R at El Sharana & 13.53 & 132.53 & 1300 & 1305 & 364 & 28 & 2070 & 1.6 \\
\hline
\end{tabular}


Table 2. Summary of results showing the different values of A and B, along with optimised values of w for the Zhang01 model.

\begin{tabular}{|c|c|c|c|c|c|c|c|}
\hline \multirow[t]{2}{*}{ Catchment } & \multicolumn{2}{|c|}{ Simhyd } & \multicolumn{2}{|c|}{ AWBM } & \multicolumn{3}{|c|}{ Zhang01 } \\
\hline & A & B & A & B & A & B & $\mathbf{w}$ \\
\hline Broken R at Old Racecourse & 1.83 & -0.39 & 1.90 & -0.53 & 1.85 & -0.81 & 0.85 \\
\hline Kolan R at Springfield & 2.60 & -0.37 & 2.33 & -0.57 & 2.27 & -1.17 & 1.75 \\
\hline Caboolture R at Upper Caboolture & 2.05 & -0.36 & 2.15 & -0.68 & 2.00 & -0.95 & 1.35 \\
\hline Gordon Brook at Fine Flower & 2.57 & -0.50 & 2.33 & -0.74 & 2.09 & -1.03 & 1.50 \\
\hline Dingo Creek at Munyaree Flat & 1.98 & -0.38 & 2.16 & -0.73 & 1.79 & -0.75 & 0.75 \\
\hline Shoalhaven River at Kadoona & 1.92 & -0.20 & 1.83 & -0.44 & 1.82 & -0.79 & 0.60 \\
\hline Genoa River at Bondi & 2.37 & -0.59 & 2.50 & -0.78 & 2.13 & -1.06 & 2.00 \\
\hline Narracan $\mathrm{Ck}$ at Thorpdale & 1.96 & -0.61 & 2.06 & -0.82 & 1.87 & -0.83 & 0.95 \\
\hline Bass $\mathrm{R}$ at Loch & 2.32 & -0.81 & 2.32 & -0.85 & 1.98 & -0.93 & 1.55 \\
\hline Mount Emu Ck at Skipton & 4.06 & -0.88 & 3.44 & -1.10 & 2.43 & -1.30 & 5.00 \\
\hline Swan $\mathrm{R}$ at The Grange & 1.87 & -0.27 & 1.85 & -0.54 & 1.76 & -0.73 & 0.40 \\
\hline Pipers R D/S Yarrow Ck. & 2.02 & -0.46 & 1.99 & -0.62 & 1.90 & -0.86 & 1.10 \\
\hline Yackandandah Ck at Osborne's Flat & 2.44 & -0.57 & 2.89 & -0.96 & 2.27 & -1.18 & 3.80 \\
\hline Jim Crow Ck at Yandoit & 2.93 & -0.79 & 2.92 & -0.98 & 2.16 & -1.09 & 2.00 \\
\hline Adelong Creek at Batlow Road & 2.31 & -0.55 & 2.66 & -0.98 & 2.15 & -1.07 & 2.50 \\
\hline Horton River at Horton Dam Site & 2.74 & -0.36 & 2.43 & -0.64 & 2.10 & -1.03 & 1.15 \\
\hline Bell River at Molong & 2.85 & -0.81 & 2.96 & -0.93 & 2.34 & -1.23 & 3.20 \\
\hline Myponga River at U/S Road Bridge & 2.76 & -0.55 & 3.13 & -0.81 & 2.29 & -1.19 & 2.70 \\
\hline Todd R at Wigley Gorge & 2.49 & 0.07 & 3.13 & -0.81 & 2.07 & -1.00 & 0.15 \\
\hline Margaret $\mathrm{R}$ at Willmot's Farm & 2.48 & -0.37 & 2.70 & -0.67 & 2.13 & -1.06 & 1.80 \\
\hline Harvey R at Dingo Rd & 2.24 & -0.37 & 2.53 & -0.63 & 2.10 & -1.03 & 1.60 \\
\hline South Alligator R at El Sharana & 2.44 & -0.59 & 2.68 & -1.15 & 1.89 & -0.84 & 0.40 \\
\hline Mean & 2.42 & -0.49 & 2.50 & -0.77 & 2.06 & -1.00 & \\
\hline Standard deviation & 0.49 & 0.22 & 0.45 & 0.19 & 0.19 & 0.16 & \\
\hline
\end{tabular}


Table 3. Correlations between A and B factors for the results in Table 2. All are statistically significant.

\begin{tabular}{|l|cccc|}
\cline { 2 - 5 } \multicolumn{1}{c|}{} & SIMHYD & AWBM & Zhang01 & \\
\hline SIMHYD & & $\mathbf{0 . 8 3}$ & $\mathbf{0 . 8 2}$ & A factor \\
AWBM & 0.66 & & $\mathbf{0 . 8 2}$ & \\
Zhang01 & 0.46 & 0.46 & & \\
& B factor & & & \\
\hline
\end{tabular}


Table 4. Correlation between major catchment characteristics and A and B factors for each of three models, including the $\mathrm{w}$ (vegetation) factor for the Zhang01 model.

\begin{tabular}{|c|c|c|c|c|c|c|c|c|c|}
\hline & Latitude & Longitude & $\begin{array}{l}\text { Area } \\
\left(\mathrm{km}^{2}\right)\end{array}$ & $\begin{array}{c}\text { Annual } \\
\text { rainfall } \\
(\mathrm{mm})\end{array}$ & $\begin{array}{c}\text { Annual } \\
\text { runoff } \\
(\mathrm{mm})\end{array}$ & $\begin{array}{c}\text { Runoff } \\
\text { coefficient } \\
(\%)\end{array}$ & $\begin{array}{l}\text { Annual } \\
\text { APET } \\
(\mathrm{mm})\end{array}$ & $\begin{array}{c}\text { Annual } \\
\text { Ep/P } \\
\text { (ratio) }\end{array}$ & $\begin{array}{c}\text { Baseflow } \\
\text { Index } \\
\text { BFI }\end{array}$ \\
\hline SIMHYD (A Factor) & 0.05 & -0.10 & 0.50 & -0.47 & -0.72 & -0.83 & -0.10 & 0.20 & -0.10 \\
\hline SIMHYD (B Factor) & -0.31 & -0.15 & -0.17 & -0.10 & 0.13 & 0.22 & 0.24 & 0.50 & -0.34 \\
\hline AWBM (A Factor) & -0.05 & -0.36 & 0.35 & -0.53 & -0.75 & -0.87 & -0.05 & 0.43 & 0.03 \\
\hline AWBM (B Factor) & 0.08 & 0.09 & -0.45 & 0.15 & 0.33 & 0.45 & -0.07 & -0.11 & -0.18 \\
\hline Zhang01 (A Factor) & 0.08 & -0.12 & 0.14 & -0.42 & -0.78 & -0.92 & -0.14 & 0.15 & 0.04 \\
\hline Zhang01 (B Factor) & -0.09 & 0.12 & -0.12 & 0.41 & 0.77 & 0.91 & 0.15 & -0.14 & -0.05 \\
\hline Zhang01 (w Factor) & 0.34 & 0.02 & 0.19 & -0.19 & -0.50 & -0.63 & -0.33 & -0.21 & 0.29 \\
\hline
\end{tabular}


Table 5. Estimated changes in flow for a large decrease in P (-15\%) and increase in Ep (+15\%), and modest increases in $\mathrm{P}(+10 \%)$ and Ep (+10\%). The largest change (highest sensitivity) is highlighted in orange and the lowest change (lowest sensitivity) in green.

\begin{tabular}{|c|c|c|c|c|c|c|c|c|c|c|}
\hline \multirow[t]{2}{*}{ Catchment } & \multicolumn{5}{|c|}{ Large Decrease } & \multicolumn{5}{|c|}{ Modest Increase } \\
\hline & $\begin{array}{l}-15 \% \text { P } \\
+15 \% \text { Ep }\end{array}$ & $\begin{array}{r}-15 \% \mathrm{P} \\
+15 \% \mathrm{Ep}\end{array}$ & $\begin{array}{l}-15 \% \text { P } \\
+15 \% \text { Ep }\end{array}$ & Mean & $\begin{array}{c}\text { Std } \\
\text { dev } \\
.\end{array}$ & $\begin{array}{c}+10 \mathrm{P} \\
+10 \% \mathrm{Ep}\end{array}$ & $\begin{array}{c}+10 P \\
+10 \% E \\
p\end{array}$ & $\begin{array}{c}\text { +10P } \\
+10 \% \text { Ep }\end{array}$ & Mean & $\begin{array}{l}\text { Std } \\
\text { dev. }\end{array}$ \\
\hline Model & SIMHYD & AWBM & Zhang01 & & & \begin{tabular}{|c|} 
SIMHY \\
D
\end{tabular} & AWBM & Zhang01 & & \\
\hline Broken R at Old Racecourse & -33.4 & -36.5 & -39.9 & -36.6 & 3.3 & 14.4 & 13.7 & 10.4 & 12.8 & 2.1 \\
\hline Kolan $\mathrm{R}$ at Springfield & -44.5 & -43.5 & -51.6 & -46.5 & 4.4 & 22.3 & 17.6 & 11.0 & 17.0 & 5.7 \\
\hline Caboolture R at Upper Caboolture & -36.0 & -42.5 & -44.3 & -40.9 & 4.3 & 16.9 & 14.7 & 10.5 & 14.0 & 3.3 \\
\hline Gordon Brook at Fine Flower & -46.0 & -46.1 & -46.8 & -46.3 & 0.5 & 20.7 & 15.9 & 10.6 & 15.7 & 5.1 \\
\hline Dingo Creek at Munyaree Flat & -35.3 & -43.4 & -38.1 & -38.9 & 4.1 & 16.0 & 14.3 & 10.4 & 13.6 & 2.9 \\
\hline Shoalhaven River at Kadoona & -31.9 & -34.1 & -39.2 & -35.0 & 3.7 & 17.2 & 13.9 & 10.3 & 13.8 & 3.5 \\
\hline Genoa River at Bondi & -44.5 & -49.2 & -47.9 & -47.2 & 2.4 & 17.8 & 17.2 & 10.7 & 15.2 & 3.9 \\
\hline Narracan Ck at Thorpdale & -38.5 & -43.2 & -40.5 & -40.7 & 2.3 & 13.5 & 12.4 & 10.4 & 12.1 & 1.6 \\
\hline Bass R at Loch & -47.0 & -47.6 & -43.7 & -46.1 & 2.1 & 15.1 & 14.7 & 10.5 & 13.4 & 2.5 \\
\hline Mount Emu Ck at Skipton & -74.2 & -68.1 & -56.0 & -66.1 & 9.3 & 31.8 & 23.4 & 11.3 & 22.2 & 10.3 \\
\hline Swan R at The Grange & -32.1 & -35.9 & -37.4 & -35.1 & 2.7 & 16.0 & 13.1 & 10.3 & 13.1 & 2.9 \\
\hline Pipers R D/S Yarrow Ck. & -37.1 & -39.2 & -41.4 & -39.2 & 2.2 & 15.6 & 13.7 & 10.4 & 13.2 & 2.6 \\
\hline Yackandandah Ck at Osborne's Flat & -45.2 & -57.8 & -51.8 & -51.6 & 6.3 & 18.7 & 19.3 & 10.9 & 16.3 & 4.7 \\
\hline Jim Crow Ck at Yandoit & -55.8 & -58.5 & -48.8 & -54.4 & 5.0 & 21.4 & 19.4 & 10.7 & 17.2 & 5.7 \\
\hline Adelong Creek at Batlow Road & -42.9 & -54.6 & -48.3 & -48.6 & 5.9 & 17.6 & 16.8 & 10.8 & 15.1 & 3.7 \\
\hline Horton River at Horton Dam Site & -46.5 & -46.1 & -47.0 & -46.5 & 0.5 & 23.9 & 17.9 & 10.7 & 17.5 & 6.6 \\
\hline Bell River at Molong & -54.9 & -58.4 & -53.6 & -55.6 & 2.5 & 20.5 & 20.3 & 11.1 & 17.3 & 5.4 \\
\hline Myponga River at U/S Road Bridge & -49.5 & -59.1 & -52.2 & -53.6 & 4.9 & 22.1 & 23.2 & 11.0 & 18.8 & 6.7 \\
\hline Todd R at Wigley Gorge & -36.4 & -59.1 & -46.1 & -47.2 & 11.4 & 25.6 & 23.2 & 10.7 & 19.8 & 8.0 \\
\hline Margaret $\mathrm{R}$ at Willmot's Farm & -42.8 & -50.6 & -47.9 & -47.1 & 3.9 & 21.2 & 20.3 & 10.7 & 17.4 & 5.8 \\
\hline Harvey R at Dingo Rd & -39.1 & -47.4 & -47.0 & -44.5 & 4.7 & 18.7 & 19.0 & 10.7 & 16.1 & 4.7 \\
\hline South Alligator R at EI Sharana & -45.5 & -57.5 & -41.0 & -48.0 & 8.5 & 18.6 & 15.3 & 10.5 & 14.8 & 4.1 \\
\hline Mean change & -43.6 & -49.0 & -45.9 & -46.2 & 4.3 & 19.4 & 17.2 & 10.7 & 15.8 & 4.6 \\
\hline Mean standard deviation & 9.6 & 9.1 & 5.3 & & & 4.2 & 3.4 & 0.3 & & \\
\hline
\end{tabular}




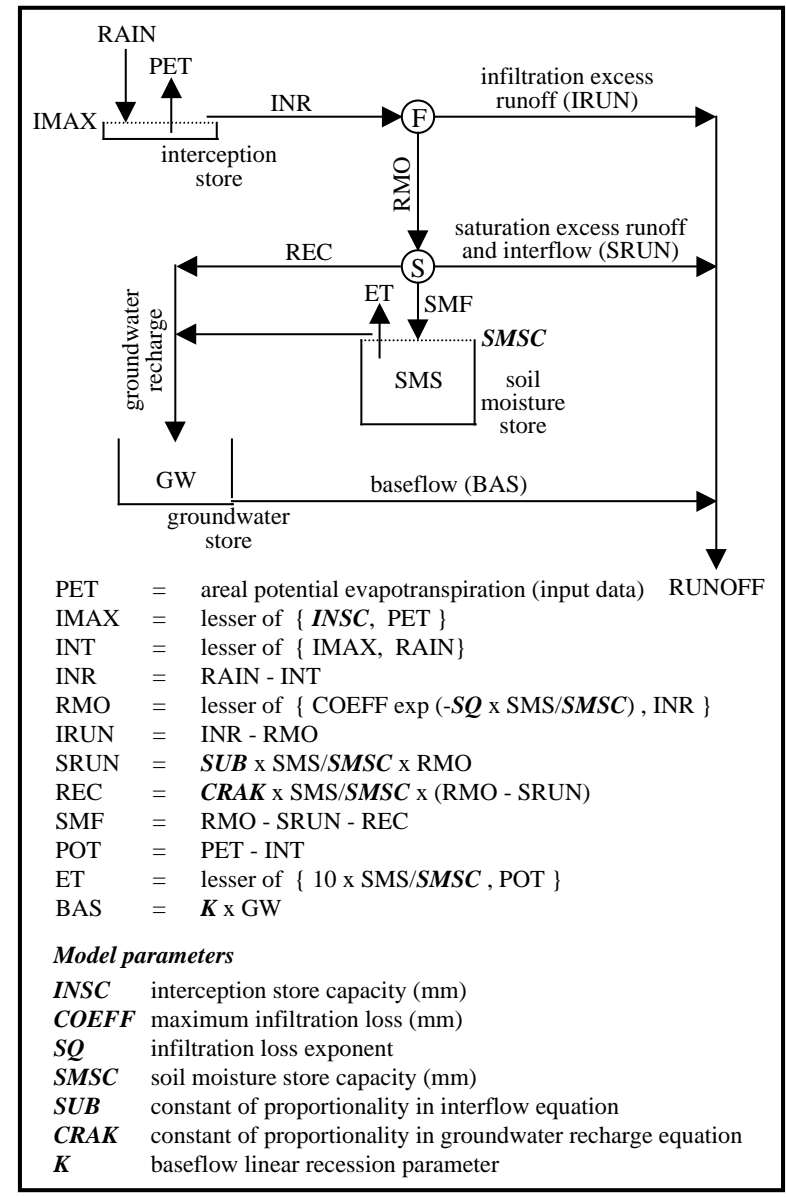

Figure 1: Model structure of SIMHYD 


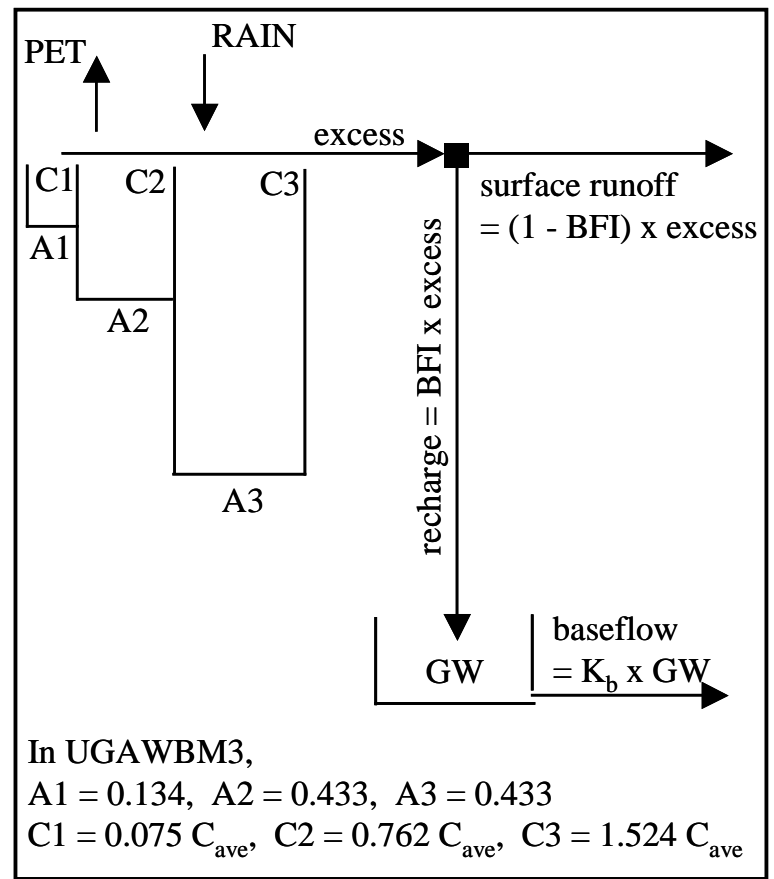

Figure 2: Structure of the AWBM model. 


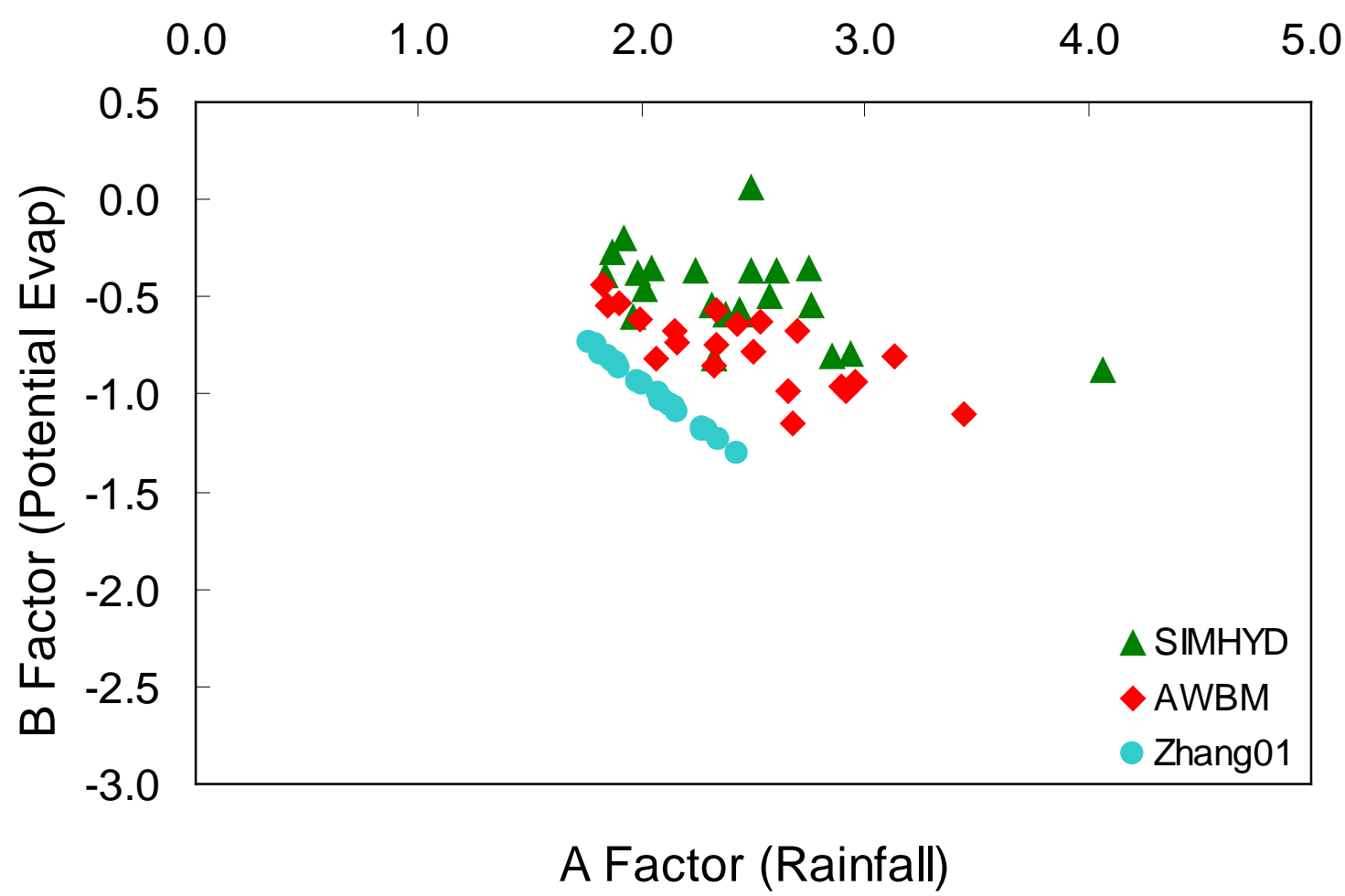

Figure 3. Relationship between A and B factors for the SIMHYD, AWBM and Zhang01 models across the 22 catchments. 


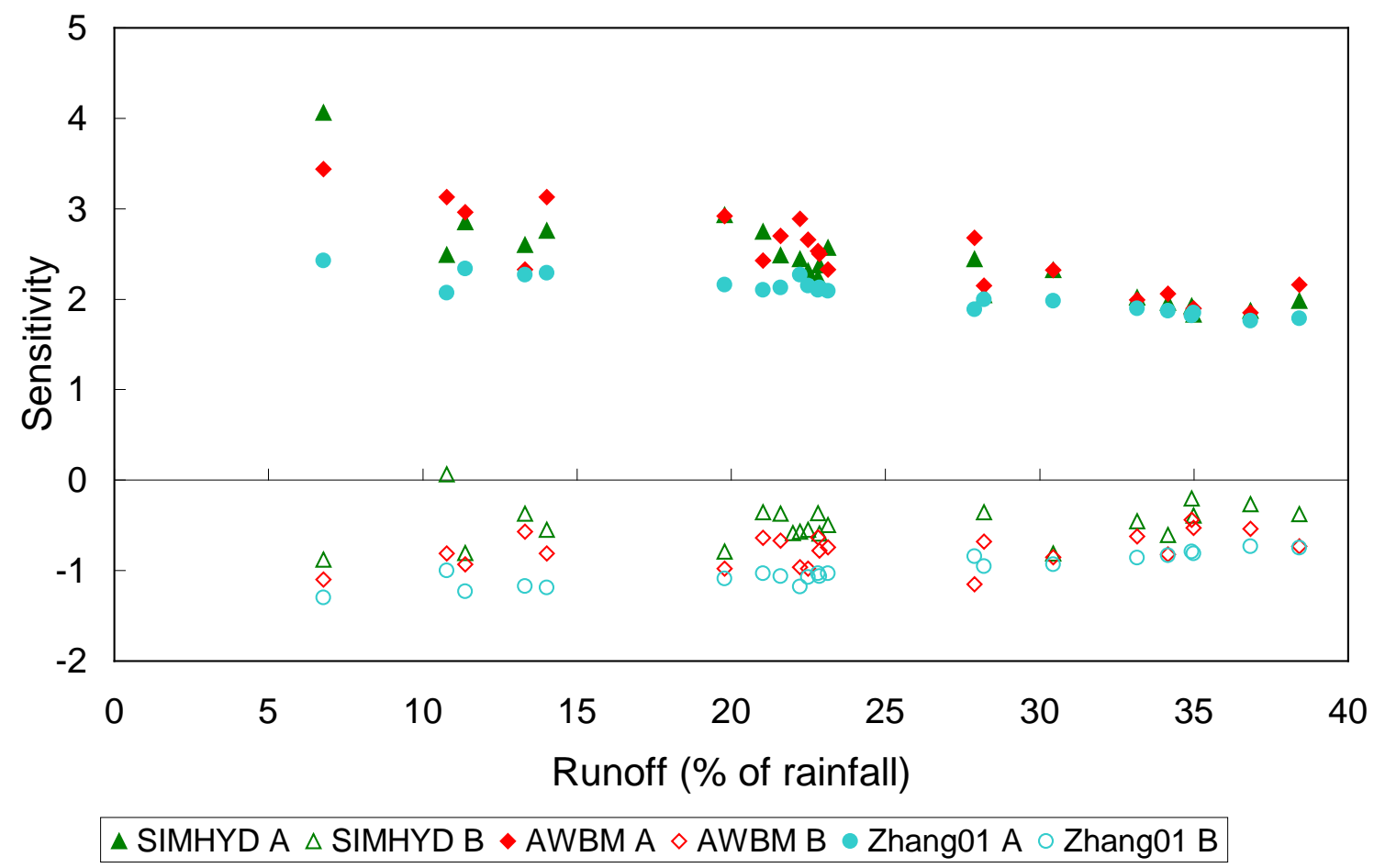

Figure 4. Sensitivity of A and B factors for the SIMHYD, AWBM and Zhang01 models plotted against runoff as a percentage of mean annual rainfall over 22 catchments. 


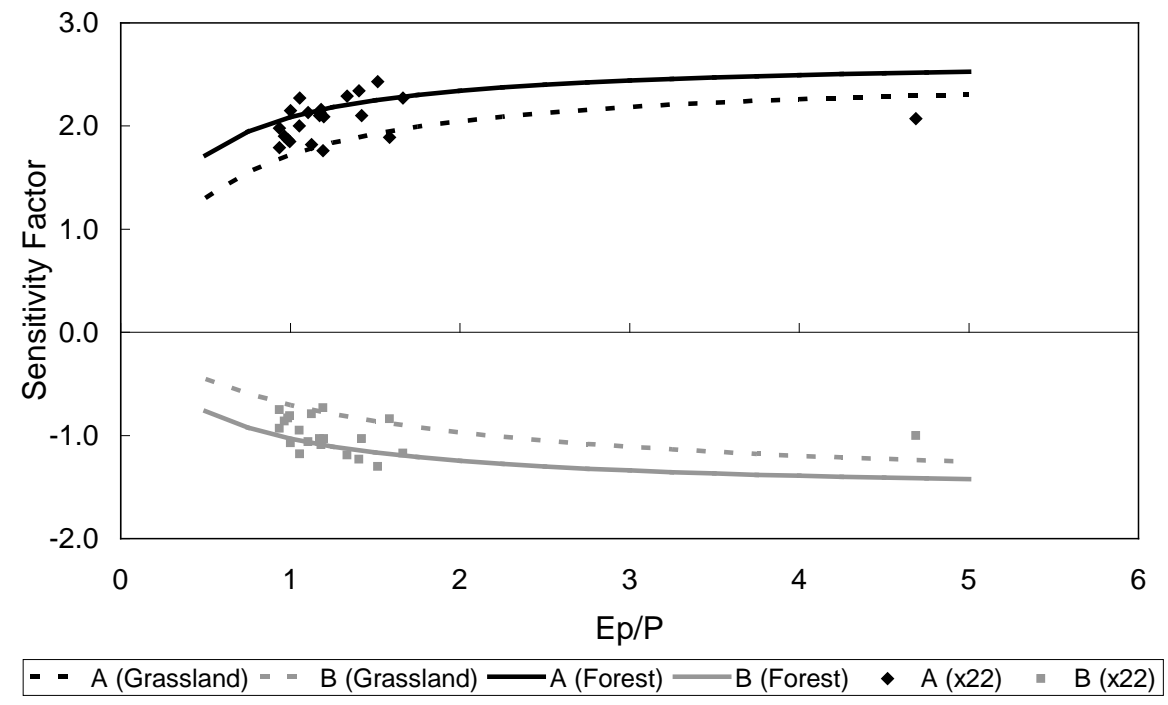

Figure 5. Relationship between $A$ and $B$ factors and Ep/P ratio for the Zhang01 model for both forest $(\mathrm{w}=2)$ and grassland $(\mathrm{w}=0.5)$. 